\title{
De pop a naîf: La mediación editorial francesa de La traición de Rita Hayworth de Manuel Puig (1964-1969)
}

Son conocidas la insatisfacción de Puig con la crítica de su propio país y su simétrica y compensatoria gratitud, no exenta de exageración, hacia sus editores extranjeros. En un artículo titulado "Loss of a readership" publicado en un semanario inglés en 1985 en el que narra su larga historia con la censura, Puig reflexiona: "He escrito mis primeras cinco novelas en español argentino pero soy leído en traducciones. Los libros están en las librerías argentinas pero nadie los compra. He perdido mi público nacional. El silencio de los medios es, posiblemente, la razón" (Puig 2007: 400). Puig se muestra como el escritor privado de sus lectores "naturales" o por lo menos directos, como el escritor que, gracias a la traducción a otros idiomas, encuentra un lectorado internacional y en este un bálsamo que mitiga el silencio castigador de la censura y de los medios argentinos. En esta casa nueva, políglota e internacional que la difusión de su literatura en el extranjero le construye, Francia, junto con Italia, es un anfitrión particularmente generoso. En el mismo artículo, Puig recuerda a propósito de la publicación La traición de Rita Hayworth:

\footnotetext{
Finalmente, en 1968 el libro fue publicado [en Argentina], con críticas indiferentes, se vendió muy poco y nadie advirtió su aparición. Mientras, Juan Goytisolo, había convencido a Gallimard para publicar La traición de Rita Hayworth y en 1969 apareció en francés y fue seleccionada por Le Monde entre los cinco mejores libros extranjeros del año. [. . .] De repente, los lectores de Argentina me descubrieron y me convertí en un best-seller (Romero 2006: 397).
}

Es notable la ironía de Puig, quien finge observar con la distancia del analista el camino de legitimación que emprende su primer libro, desde fuera para dentro, desde la gloria extranjera, mejor dicho, parisina, hacia el reconocimiento doméstico, tardío y provinciano. En estas declaraciones se dibuja una compleja figura de autor que se irá desarrollando y enriqueciendo con los años y en la cual el extranjero cumple una doble función, paradójica, de escenario de legitimación, y, al mismo tiempo, de triste refugio para un escritor solo, separado de

Gersende Camenen, Université Gustave-Eiffel

D Open Access. (C) 2021 Gersende Camenen, published by De Gruyter. (cc) BY-NC-ND This work is licensed under a Creative Commons Attribution-NonCommercial-NoDerivatives 4.0 International License.

https://doi.org/10.1515/9783110713015-018 
sus lectores y de su lengua ${ }^{1}$. En esta imagen que acompaña la obra del escritor y condiciona en gran parte su lectura, Francia es uno de los espacios de acogida que entiende y reconoce al escritor. Puig alarga la lista de escritores argentinos e hispanoamericanos consagrados por Francia y cuya recepción doméstica dependió en gran parte del llamado "efecto París” (Casanova 2008: 161). La correspondencia de Puig con su familia nos da a leer la versión íntima, exultante y algo exagerada del efecto que podía tener la publicación francesa sobre la carrera del escritor. El hijo feliz comunica así su orgullo:

Cada vez que lo pienso de nuevo me cuesta creerlo ipublicado por Gallimard! Debe ser un caso único en la historia de la literatura argentina, qué poroto, si es una cosa de no creer. Me parece que esto va a ayudarme mucho para las demás ventas porque Francia en literatura es siempre la que mueve la batuta (Puig 2006: 260).

La reconstrucción de los caminos que emprendió la primera novela de Puig por el mundo editorial francés nos llevará a interrogar y matizar dicha imagen de un mundo editorial francés que acoge con los brazos abiertos al escritor y comprende perfectamente su obra. Los archivos de las dos editoriales francesas Seuil y Gallimard, por las cuales circularon los manuscritos de La traición de Rita Hayworth, permiten arrojar una luz nueva sobre el papel que desempeñó el sistema editorial y crítico francés en la construcción de una figura central de las letras hispanoamericanas.

\section{El escritor pop y la mirada exterior}

En la contratapa de la edición original de Boquitas Pintadas, una cita de Manuel Puig presentaba su segunda novela como "un folletín con el cual, sin renunciar a los experimentos estilísticos iniciados en su primera novela, intenta una nueva forma de literatura popular". La frase concentraba el ambicioso programa literario de un joven escritor cuya primera novela, recordaba la editorial Sudamericana en la misma contratapa, había sido seleccionada por "el prestigioso diario Le Monde entre las trece mejores novelas extranjeras de la temporada 1968-1969”. En estas dos citas, que constituyen lo esencial de un breve paratexto editorial que

1 Sobre el "mito" Puig y su uso de los mitos colectivos argentinos, véase Corbatta (2009). El desencuentro de Puig con Buenos Aires, el melodramático desamor se repite una y otra vez en sus entrevistas y termina siendo un tópico de su propio discurso sobre su recepción argentina, como se aprecia en el título Buenos Aires, cuándo será el día que me quieras. Conversaciones de la recopilación de Almada Roche (1992). 
presentaba la novela a sus lectores argentinos, se encuentran, sintetizados por la retórica publicitaria, los dos rasgos que no tardarán en definir el lugar ocupado por la obra y la figura de Manuel Puig en el campo literario argentino: la síntesis de lo experimental y de lo popular, por un lado, y la legitimación de su obra por la crítica extranjera, por el otro ${ }^{2}$.

En un libro publicado en 2003, que ha tenido una importante repercusión sobre la crítica, y, en este sentido, sirve de marcador, Graciela Speranza retoma estas dos categorías, ilustrando en cierta forma, la longevidad de la lectura crítica de Puig que la contratapa de la edición original de Boquitas Pintadas ya sintetizaba en 1969. El ensayo de Speranza propone una clara definición de la poética de Puig y, sobre todo, en lo que nos toca, una reflexión sobre los efectos culturales e ideológicos de la obra del escritor. A partir de un cotejo de las prácticas narrativas del escritor con las técnicas del pop art cuya difusión en Buenos Aires es contemporánea de la escritura de la primera novela de Puig, Speranza muestra cómo este concibe, a la manera de Andy Warhol, un "arte popular que incorpora íconos y objetos de consumo masivo mediante una sutil transformación que los convierte en arte, sin que pierdan por ello la propiedad objetiva que los vincula con la experiencia cotidiana y sin producir por eso efectos paródicos o críticos” (Speranza 2003: 14).

Desde La traición de Rita Hayworth, la "sutil transformación” mencionada por Speranza consiste, como se sabe, en reproducir los discursos y lenguajes orales y escritos no literarios sin hacer intervenir una instancia narradora. De esta manera, los fragmentos de conversación cotidiana, las cartas al lector, la redacción escolar, para tomar unos ejemplos en la vasta masa discursiva que maneja Puig en sus novelas, se yuxtaponen sin explicación ni jerarquía y conservan así la emoción de lo vivido, un vínculo con la experiencia evocado por Speranza, que seduce al lector a la vez que le impide determinar la posición crítica del autor respecto al mundo que narra, $y$, en especial, la cultura de masas. La narrativa de Puig representa algo más que una simple novedad al emplear procedimientos que impiden una lectura ideológica unívoca de la sociedad de consumo. Marca una ruptura que Speranza resume con el seductor calificativo de "escritor pop", entendido como aquel que opone el montaje de voces anónimas al estilo como marca del sujeto individual y borra las fronteras entre cultura alta y de masas, y, de esa manera, como reza el título del ensayo, señala el "fin de la literatura",

2 Sobre el primer rasgo definitorio véase, entre otros, Rodríguez Monegal (1972), Catelli (1982), Pauls (1986), Giordano (1996, 1998) y Amar Sánchez (1998). Sobre el segundo rasgo, ver de Diego (1998). 
entiéndase el final del régimen moderno de la literatura fundado en los valores de originalidad y estilo ${ }^{3}$.

La radicalidad del proyecto literario de Puig explica, según Speranza, el desconcierto de la crítica argentina ante la primera novela del escritor y destaca, en cambio, la "mirada exterior" que posa sobre ella una mirada esencialmente francesa en su opinión, que sí entiende y celebra la novedad de la escritura del novelista. En efecto, según la ensayista argentina, "La traición de Rita Hayworth deberá esperar hasta la edición francesa del 69 en Gallimard para encontrar un reconocimiento público amplio de la originalidad de sus procedimientos narrativos" (Speranza 2000: 25) ${ }^{4}$.

Ante el éxito crítico de la novela en Francia, parece legítimo investigar el papel que desempeñaron los editores franceses en su publicación. Varias son las preguntas que se pueden hacer al respecto: ¿Cómo y qué entendieron los editores y diferentes mediadores franceses de la "novedad" estilística y cultural de la narrativa de Manuel Puig, en una palabra, de su estética “pop”? ¿Cuál fue su grado de intervención en el programa literario del escritor? ¿Cómo el escritor y su novela fueron presentados al lector francés por sus editores y por sus primeros lectores, los periodistas que reseñaron la novela? $\mathrm{O}$, dicho de otra forma, ¿quién es el Puig seleccionado entre los mejores escritores del año 1968 por Le Monde?

\section{La saga de Rita Hayworth}

Convendría contestar, primero, a otra pregunta, más práctica y concreta; ¿Cómo llegó el libro a las manos de los editores franceses? La respuesta a esta última pregunta es relativamente larga. La primera razón es que el relato de la publicación francesa de La traición de Rita Hayworth se inserta en la folletinesca historia de la publicación de la novela en español o en lo que su traductora, amiga y biógrafa Suzanne Jill Levine ha llamado “la saga de Rita Hayworth”. Las peripe-

3 El calificativo circula tempranamente desde las primeras reseñas de Boquitas pintadas para definir al escritor y su estética, como lo recuerda Graciela Speranza en su ensayo, para luego convertirse en un hilo conductor dentro de la crítica. Véase, entre otros, Páez (1995) y Guedán (2018). Speranza da un sentido preciso al calificativo "pop" al asociarlo con el final de la literatura moderna, como régimen de producción y sistema de valores.

4 La misma organización del ensayo de Graciela Speranza pone de relieve este gesto de reconocimiento por parte de la crítica francesa ya que no empieza con la definición de la poética de Puig sino con el análisis comparado de la recepción de La traición de Rita Hayworth, en la Argentina y en el extranjero, en un capítulo titulado "La mirada exterior" (pp. 25-31) esencialmente dedicado a la recepción periodística francesa. 
cias de lo que, por momentos, adquirió para el autor la densidad dolorosa de un melodrama, forman, según Levine, dos episodios: la escritura de la novela entre 1962 y 1965 y la transformación del manuscrito en libro para el mercado hispanohablante entre 1965 y 1968 (Levine 2002: 131-180). La consulta de los archivos de las editoriales Gallimard y Seuil permite añadir un tercer episodio a esta saga, el de su publicación y recepción en Francia. Aunque, en vez de tercer episodio, sería más acertado hablar de un tercer hilo narrativo, ya que el relato de la publicación de La trahison de Rita Hayworth en francés no es posterior y empieza también en 1965, según la trama cronológica de Levine. Los archivos de las editoriales francesas, como veremos a continuación, llevarán a modificar sensiblemente la cronología de los acontecimientos.

En la "saga" reconstruida por Levine, el punto de partida de la novela es un texto titulado "Pájaros en la cabeza" que Puig empieza a escribir en el centro experimental de cinematografía de Roma donde era becario y que se conserva hoy en sus archivos de La Plata. El propio Puig ha comentado las condiciones de escritura de este texto: para alejarse de su material autobiográfico y no recaer en los errores de la escritura de guiones, escuchó la voz de una tía describiendo un patio de la provincia argentina y, poco a poco, fue copiando lo que le dictaba esta voz surgida del pasado. Es este manuscrito, germen de la técnica narrativa del escritor y también de una poderosa ficción de origen de su escritura, que Puig entrega a Néstor Almendros, el futuro fotógrafo de cine oscarizado y entonces compañero de estudios en el centro experimental de cinematografía dirigido por Cesare Zavattini, en Roma. En abril de 1965, a la manera de un agente literario informal, Almendros confía el manuscrito a su compatriota Severo Sarduy, lector para Claude Durand, entonces joven y flamante director de la colección "Cadre vert" de Seuil, la misma que en 1968 lanza Cent ans de solitude y permite al futuro "emperador Claudius” de la editorial francesa, dar su primer "batacazo” (Dosse 2014: 76).

Mientras tanto, el manuscrito avanza por los caminos españoles del boom hasta llegar a ser finalista del premio Biblioteca Breve de Seix Barral a finales de 1965. En lo que se convertirá en un episodio conocido del boom, Mario Vargas Llosa se niega a premiar la novela de Puig, un autor que, a su modo de ver, escribe “como Corín Tellado” (Guedán 2018: 37). Más allá de lo que se podría leer como un simple chiste malvado, la vehemencia del escritor peruano evidencia las diferencias estilísticas y políticas que separan a Puig de los que él llamará, con un rencor persistente, los "barralistas" (Puig 2006: 242). La literatura, para Vargas Llosa (o Juan Carlos Onetti quien aduce el mismo argumento para negar a Boquitas Pintadas el premio de la revista Primera Plana en 1969), es la manifestación de un estilo, de una visión que unifica y da un significado al mundo narrado. Desde este marco crítico, sartreano hasta cierto punto, la literatura de Puig es estéticamente mala y moralmente condenable por su frivolidad apolítica. 
Con esta primera frustración, empiezan los infortunios editoriales de la novela, que va a sufrir sucesivamente la censura de editores y regímenes dictatoriales para, finalmente, ver la luz en la editorial del temerario Jorge Álvarez en 1968, es decir, tres años después del primer contrato con Seix Barral ${ }^{5}$. Infortunios que en el discurso del escritor convertirán la censura en un "mecanismo de legitimación de su posición alejada de las posturas dominantes en el campo literario argentino y latinoamericano", la de un "excéntrico en su manera de entender el compromiso del escritor con la realidad [que] no se identifica con la figura del intelectual sesentista” (Goldchluk/Romero 1996: 393).

En este océano de tristeza y desilusión, "el único toque de glamour que [le] ayudó a soportar tres años de frustración editorial” (Levine 2003: 168), es la oferta de Gallimard. En la misma primavera de 1965, Juan Goytisolo, entonces lector para la editorial, defiende el manuscrito que Néstor Almendros le ha propuesto poco después de que Severo Sarduy no lograra imponerlo en Seuil (Puig 2006: 156). La publicación en francés compensa ampliamente la censura doméstica ${ }^{6}$.

En este momento del relato biográfico parece que la satisfacción que brinda el reconocimiento de Seuil y Gallimard, dos instancias con fuerte capital simbólico, mitiga la frustración y la amargura de Puig ${ }^{7}$. Lo consuela también el sentimiento de haber encontrado a sus lectores (su "quinteto de oro" formado por el amigo Mario, Néstor Almendros, Severo Sarduy, Guillermo Cabrera Infante, Juan Goytisolo, y ampliado luego a Emir Rodríguez Monegal, quien publica en Mundo Nuevo capítulos de la novela inédita) quienes no son solamente amigos y apoyos, sino aliados estéticos e ideológicos (Levine 2012: 173-180). Por los pasillos de SaintGermain, la sede de las editoriales parisinas y corazón del mundo intelectual

5 Estas tres "censuras" sucesivas son el rechazo editorial de Barral, la del editor mexicano y finalmente la de un linotipista que impide la publicación de la novela por Francisco Porrúa en Sudamericana. Sobre este punto, véase Speranza (2003: 19-25). Las malas relaciones de Puig con Carlos Barral debidas a divergencias políticas y personales han sido comentadas por Levine (2012: 166).

6 Aunque los editores franceses también aplican la censura, según el escritor. En su opinión, El beso de la mujer araña fue rechazado en Gallimard, como lo fue por su editor italiano histórico por razones políticas: el retrato del homosexual revolucionario empañaba la imagen del militante setentista. El episodio engrosa la lista de censuras y participa en la construcción de la imagen de excepcionalidad del escritor. Sobre este episodio, véase Levine (2012: 279), Goldchluck/Romero (1996: 395) y Romero (2006: 399).

7 El 2 de noviembre de 1965, después de tratar con "gente de letras" en París, escribe a su familia: "Sentir un reconocimiento de parte de la gente es para mí en este momento una verdadera necesidad, si no me parece que soy un empleado de Air France aficionado a las letras y chau. En cambio para ellos soy una realidad luminosa, un astro en el firmamento literario, qué plato” (Puig 2006: 182). 
desde la posguerra, se murmura el nombre de un joven escritor argentino que en una carta a Guillermo Cabrera Infante se queja de "haber sido víctima del subdesarrollo" y espera “que lo rescate el Viejo mundo" (Speranza 2003: 26). Contrastemos ahora esta imagen con la que nos ofrecen los archivos de las dos editoriales parisinas.

\section{Personajes, canarios y vampiresas}

En los archivos de la editorial Seuil, depositados en el Institut Mémoires de l'édition contemporaine (IMEC), se conservan los informes de lectura de la novela redactados por los lectores de esa casa. A través de ellos, podemos seguir el tránsito del manuscrito de la futura novela por una de las principales editoriales parisinas, así como el papel que consecutivamente pudieron desempeñar las lecturas editoriales en la génesis de la novela y, en especial, el de una figura clave en la mediación del libro de Puig, un lector y futuro editor de literatura hispanoamericana en la misma editorial, Severo Sarduy.

La primera sorpresa que deparan los archivos relacionados con La traición de Rita Hayworth es una fecha. El primer informe es de abril de 1964, anterior de casi un año al momento en que el escritor termina el manuscrito de la novela. Es decir, que en la editorial se inicia muy tempranamente el proceso de selección, lectura, interpretación y evaluación de lo que todavía no es la novela final. No es extraño que una novela circule por editoriales, se lea, se comente y que esta serie de operaciones no desemboque en la publicación de la novela por la editorial. Es, en realidad, lo más frecuente, siendo la publicación final una excepción. Sin embargo, el interés de este caso es doble: primero, porque el proceso de mediación editorial es precoz y, segundo, porque dicha precocidad propicia la eventual intervención de la editorial en la génesis de la novela, como veremos ahora.

El autor del primer informe es Alain Rouquié, historiador y politólogo especialista de América Latina, cuya carrera ilustra los profundos vínculos que unen la investigación científica, la diplomacia y las responsabilidades institucionales en el latinoamericanismo francés ${ }^{8}$. En 1964, el futuro embajador de Francia en el Salvador, México y Brasil, y actual director de la Maison de l'Amérique latine, es todavía un joven universitario, agrégé d'espagnol y que ya lee con frecuencia textos y manuscritos en lengua española para la editorial parisina. Su función de

8 Ver https://data.bnf.fr/fr/11922857/alain_rouquie/ (última visita: 25/05/2020). 
lector en Seuil ilustra, además, la compenetración de los medios editoriales y universitarios.

El texto que Rouquié evalúa se titula "los personajes" y se presenta como el manuscrito inacabado de un "proyecto" que no tiene definición genérica y se compone de siete monólogos, es decir, apenas la mitad de la versión final de la novela que consta de quince capítulos. El título del manuscrito, formal, técnico, "remático" (Genette 1987: 83), opaca un posible contenido semántico, impidiendo cualquier intento de identificación cultural o nacional por parte del lector. Parece obedecer, al contrario, a los criterios del Nouveau Roman, que desde finales de los años cincuenta definen el horizonte de la novela francesa, o por lo menos constituyen su polo más vanguardista, tal y como se va definiendo con las novelas de Alain Robbe-Grillet defendidas por la editorial Minuit de Jérôme Lindon, en la prescriptiva de Nathalie Sarraute en L'ère du soupçon (1956) que desacredita el personaje balzaciano y promueve su vaciamiento y, sobre todo, en los textos del crítico Jean Ricardou publicados en la revista Tel Quel editada por la propia Seuil ${ }^{9}$.

En su informe, Rouquié elogia la perfección de los siete monólogos interiores que constituyen el manuscrito evaluado, pero lamenta que los mismos monólogos no lleguen a componer un relato. Nótese que, como Vargas Llosa, Rouquié subraya la falta de unidad en el texto de Puig pero, a diferencia del escritor peruano, no atribuye esta carencia a la ausencia de una voz narradora unificadora, ausencia que, por lo demás, no parece perturbarlo. Rouquié estima que el argumento de lo que todavía es un conjunto de solo siete monólogos es frágil. En otros términos, y para contestar a una de nuestras preguntas iniciales sobre la recepción de la novedad estilística de la novela en las editoriales francesas, este primer lector de Seuil no rechaza la principal innovación formal de Puig, la multiplicación de voces. Manifiesta, al contrario, cierta confianza en el porvenir del texto, al estimar que el "collage" de voces se podrá consolidar en la futura "novela" o en "alguna obra más madura”, corrige el evaluador, con un matiz que sugiere que la novela no es el único molde genérico posible en el mundo editorial.

El título a lo Nouveau Roman y la fecha temprana de la entrega parecen confirmar la importancia que tenía para Puig la mirada parisina. ¿Quería seducir imitando, adoptando los códigos de la última modernidad literaria para apropiársela y ser reconocido por quien la define? Es tentador imaginarlo si no fuera porque el propio Puig, en una carta a su familia de abril de 1964, rechaza,

9 En 1964 Alain Robbe-Grillet había publicado la novela Les Gommes (1953); Michel Butor L'emploi du temps (1956), La modification (1957), Degrés (1960); Claude Simon L'herbe (1958), Le palace (1962). 
irritado, este "título asco", que “el lector de Editions du Seuil” (posiblemente Severo Sarduy) "le puso para presentar” el manuscrito (Puig 2006: 105). Su reacción revela una gran ambivalencia hacia el mundo editorial francés. Por un lado, solicita su interés, ansioso de encontrar lectores que entiendan su escritura y la legitimen. Su propio gesto, mandar un manuscrito inacabado a una prestigiosa editorial, ilustra la audacia del escritor novel y extranjero. De hecho, Puig no disimula su satisfacción por haber logrado que lo publique una editorial francesa. A finales de 1966, a punto de firmar su contrato con Gallimard, explica a su familia los engranajes de la edición de literatura extranjera en Francia, para que pueda comprobar el alcance de su hazaña:

Yo no sé cómo tuve el coraje de proponerme algo así, un desconocido pretender que le traduzcan una obra de buenas a primeras. Porque en general se traduce a alguien después de haber consolidado su prestigio en su idioma. Siempre una traducción entraña primero el gasto enorme de la traducción y segundo el riesgo de que la obra pierda mucho del valor original, así que "Gallimard” estará más que entusiasmada (Puig 2006: 260).

Pero, por otro lado, no parece compartir los criterios de valor de este mismo mundo editorial que solicita. Puig no aprecia el título que los lectores de Seuil dan a su manuscrito, "estas cosas raras" del mundo parisino que en su carta de 1964 designa como una jerigonza, una "insaburida", empleando el dialecto parmesano que salpica su correspondencia familiar y subraya más aún su actitud, por no decir su pose, anti-intelectual. El rechazo epidérmico del título no manifiesta solamente la coquetería de un escritor incipiente y presumido que no tolera comparaciones, sino que expresa una divergencia estética fundamental. Puig no cree en el Nouveau Roman, que no le parece ser una auténtica fuente de renovación de la narrativa sino una aventura pretenciosa y aburrida. En una carta posterior, explica a su madre, quien le pregunta por "Robbe-Grillet" y "los latinoamericanos modernos", que "ante todo pretendió eliminar la visión subjetiva de las cosas, quiere describir las cosas como son (sobre todo el marco material en que se mueven los personajes) y no como las siente el escritor” y dictamina, rotundamente, “es muy interesante y refinado pero un PLOMO para el lector" (Puig 2006: 248). Su principal ángulo de ataque al Nouveau roman, la falta de consideración por el placer del lector, indica la dirección que él toma en sus propias búsquedas y que consiste en optar por la seducción de las formas populares de narrar. El Nouveau Roman se convierte en el anti-modelo de cuyos "trucos" debe protegerse mientras escribe Boquitas Pintadas, "se me pegaron cosas de un francés a la picota, es un plato, las voy a sacar” (Puig 2006: 248).

El segundo informe conservado en los archivos de Seuil data de abril de 1965 y lo firma Severo Sarduy. La fecha parece indicar que el manuscrito evaluado es 
el de la versión final de La traición de Rita Hayworth, aunque este título no aparece en el documento. El texto presentado por el autor se llama ahora "El canario del chico de enfrente" y lo acompaña otro título, "La trahison de la vampiresse", que parece haber sido añadido al primero.

Dejemos de momento la cuestión del doble título para interesarnos en dos efectos producidos por la incertidumbre que rodea la autoría de los títulos de los manuscritos. El primero concierne la génesis de La traición de Rita Hayworth y el papel que pudieron desempeñar sus lectores editoriales en ella. Los diferentes títulos que se encuentran en los informes pueden interpretarse como huellas de las numerosas conversaciones que rodearon un manuscrito que pasó por muchas manos (Levine 2012: 78-80). Leído a partir de la densidad material y temporal que fueron creando los vaivenes del objeto-manuscrito, el propio informe de lectura editorial deja de ser un documento de trabajo que registra, describe y analiza, para cobrar otra tesitura, más afectiva, la de una grabación de voces que acompaña el proceso genético de la novela. El conjunto formado por los informes de lectura dobla, en el sentido cinematográfico de la palabra, la composición de la novela, al producir su propio relato en el cual se responden las voces escritas de los lectores.

El segundo concierne la exégesis de la novela. Leído hoy, desde el presente de una novela acabada, editada, publicada, reeditada y engrosada por sucesivas lecturas críticas, el conjunto de informes de lectura de Seuil produce un efecto interesante: dispone en diacronía las capas estilísticas y discursivas que conforman sincrónicamente la novela final y conviven en ella sin que la versión final las anule. Así la lectura sucesiva de los informes no solo contextualiza las interpretaciones posibles de la novela, sino que destaca el hecho de que convivan en la novela. En La traición de Rita Hayworth, en efecto, permanece algo del ejercicio de estilo a lo Nouveau Roman que pudo transformar los pampeanos “pájaros en la cabeza” del pre-texto inicial de Puig en analíticos y parisinos “personajes”. En La traición de Rita Hayworth se lee también una crónica de provincia, con su "canario del chico de enfrente”. Nótese de paso que, con el retorno a la provincia del segundo título, vuelven los pájaros y cobra más protagonismo Toto, el niño de la novela y el autor del sintagma, es decir, que la novela encuentra la densidad argumental, o vale decir la carne humana, que faltaba, según Alain Rouquié, a los formalistas "personajes” del primer título. En cuanto a "La trahison de la vampiresse", exhuma la veta camp de la formula genérica final de La traición de Rita Hayworth, la que conocemos, la novela de aprendizaje pasada por el filtro freudiano de Hollywood.

Resulta muy probable que el segundo título del manuscrito, "La trahison de la vampiresse", sea un agregado de Severo Sarduy, ya que aparece en el cuerpo del informe, con los comentarios y no con el resto de los datos iniciales que identifican el texto evaluado. Con esta propuesta de título en francés, Sar- 
duy se dirige al editor (Claude Durand, director de la colección "Cadre vert") para traducirle el título adoptando los nuevos códigos culturales que manejaba perfectamente. Sarduy cambia el título infantil y provinciano por un título más sensual e inquietante, un título que encarna perfectamente la postura camp. "La trahison de la vampiresse" suena en efecto como un anticipo del bolero "La gran tirana” de 1968 ("Según tu punto de vista/Yo soy la mala/Vampiresa en tu novela/La gran tirana”), interpretado por La Lupe, la cantante cubana que Susan Sontag incluye en el canon del camp en su ensayo de 1964, Notes on camp. Con este bautizo, Sarduy supera la simple función de redactor de informe para asumir la responsabilidad de un editor y gozar de sus privilegios. El primero es el de dejar en el texto final de la novela la huella de su lectura crítica. La sustitución del título del autor manifiesta, en efecto, un doble gesto de comprensión e interpretación del texto que no solo aclara su sentido, sino que lo orienta o incluso lo va creando. Sarduy, quien todavía no ocupa el cargo de editor, no puede llevar a cabo un proceso que consiste en "ofrecer su lectura mediante una construcción, conceptual y formal (papel, formato, presentación, traducción)" (Ouvry-Vial 2007: 72), y no es de sorprender que su lectura camp no despierte interés en un medio editorial poco abierto aún a este tipo de lectura. Pero sí es notable la manera en que supera las prerrogativas del redactor de informe en un sistema, el de Seuil, profesional y jerarquizado (Dosse 2014: 80). Por su lado, Puig, ansioso de ser publicado, sabe que "de él depende todo" (Puig 2006: 146).

El análisis de la novela que hace Sarduy confirma todo el interés hermenéutico e histórico que puede llegar a tener un informe de lectura e ilustra también su particular tesitura afectiva. Sarduy defiende el libro con pasión y desarrolla una argumentación que revela los distintos lugares desde donde lee el libro. Si bien el manuscrito le parece “descosido” (en abril de 1965, año del premio) y la escritura imperfecta, declara que "este texto sobre la infancia es el más conmovedor que ha leído en español”10. Esta primera apreciación general toca así la sustancia emocional de la novela para sugerir su dimensión universal. Sarduy hace las veces de un editor que "juega el papel del lector, extrapola a partir de su propia reacción de lector, anticipa sobre lo que será la del público” (Ouvryvial 2007: 73). Para ilustrar su argumento, Sarduy califica al personaje de Toto, el niño alienado por la ficción de Hollywood, como un "Emma Bovary de la pampa”. La referencia le añade además otro valor a la novela, el que confiere la comparación con un clásico nacional. Como redactor de informe, Sarduy sabe perfectamente que el libro debe franquear esta primera barrera de reconoci-

10 El informe está redactado en francés; la traducción es nuestra. 
miento y legitimación para pasar el filtro editorial. Pero sabe también que el mundo editorial se alimenta de novedad, y procura proveérsela. Con Puig, proclama Sarduy ahora con la confianza del crítico, y no del simple lector de editorial, la literatura latinoamericana ha encontrado su "pop-art", no solo porque en la novela "proliferan los objetos publicitarios" sino porque su lectura produce un singular efecto de burla y ternura. En la conclusión de su informe, Sarduy da una perfecta definición de lo que siente un lector de Puig y que sintetiza el uso de la cultura pop: "Uno ríe mucho y luego se siente culpable de haber reído, y luego se siente ridículo de sentirse culpable, es decir, que se ríe de nuevo".

Es posible que en el epíteto "escritor pop" sea una ocurrencia de Sarduy, quien lo utiliza desde 1965 en su informe, pero lo interesante es que el calificativo circula en la temprana recepción crítica latinoamericana de Puig. Lo usa José Manuel Oviedo en una reseña de la novela en El comercio (Speranza 2003: 26) en 1968, y lo emplea también Emir Rodríguez Monegal en diciembre de 1967 para presentar el segundo fragmento de la novela inédita que se publica en su revista Mundo Nuevo (Rodríguez Monegal 1968: 21). Y el término se encuentra a menudo en la correspondencia de Puig, que se muestra ansioso por encontrar lectores que entiendan su estilo, lectores al tanto de los "gustos actuales", y en especial del “ambiente pop” (Puig 2006: 234). Utilizado por los intelectuales, el término "pop”, analiza Speranza con mucha agudeza, es una categoría del gusto que les permite apropiarse de la inmediatez seductora de la cultura masiva conservando al mismo tiempo sus privilegios en el ejercicio del poder cultural (Speranza 2003: 57). La aparición del adjetivo en los informes de Sarduy, con el particular sentimiento de culpabilidad y liberación que sugiere y que resume perfectamente la cita anterior, muestra que él actuaba de puente entre este poder cultural de la crítica latinoamericana y el mundo editorial francés, intentando importar un discurso crítico elaborado, destinado a modelar la novela de Puig y presentarla como la manifestación, por no decir la epifanía, de una absoluta novedad y de una sofisticada modernidad. Al atribuir un título y desarrollar un discurso crítico para presentar la novela, Sarduy se fogueaba como editor. Sin embargo, su argumento de la novedad absoluta, de un Puig “escritor pop” no fue suficiente para convencer a los editores de Seuil.

\section{IV ¿La trahison de Gallimard?}

Gracias al diligente Goytisolo, que desde finales de 1965 vela por el bien de la novela, en el otoño de 1966, el manuscrito está en manos del responsable de la 
colección "Du monde entier”, Dionys Mascolo" ${ }^{11}$. Desde su creación en 1931, “Du monde entier” es la gran colección especializada en literatura extranjera de Gallimard. Pensada a partir de la colección de referencia de literatura francesa de la editorial, la "Blanche", comparte con ella los mismos criterios de "excelencia literaria”. Pretende garantizar a su lectorado el acceso a la flor y nata de la literatura extranjera, para lo cual se precia de operar una rigurosa selección guiada, asegura el texto de presentación de la colección en 1936, por la sensibilidad y el patrocinio de "escritores franceses" conocidos ${ }^{12}$. Entrar en la colección, de la mano de un escritor francés, es sin lugar a dudas la mejor manera de obtener su carta de ciudadanía en la Republica mundial de las letras. Este funcionamiento tiende sin embargo a modificarse a partir de la posguerra, momento en que la colección se autonomiza de su modelo, pasa a manos de especialistas de las distintas literaturas extranjeras representadas en la colección y se profesionaliza la selección de textos.

El responsable de la colección presenta la novela a Claude Gallimard con el dossier de los informes entusiastas de cuatro lectores, Tomás Segovia, Juan Goytisolo, Maurice Edgar-Coindreau (editor y traductor de literatura norteamericana en la misma colección) y el argentino Héctor Bianciotti, lector desde principios de los años sesenta ${ }^{13}$. Sin embargo, Claude Gallimard, consciente de la urgencia de responder a Carmen Balcells (agente de Puig para esta única novela; Levine 2012: 175), quiere la opinión de Claude Couffon, uno de los princi-

11 Dionys Mascolo (1916-1997) fue un militante político, ensayista y editor. Íntimo de Marguerite Duras y Robert Antelme fundó con ellos el "groupe de la rue Saint-Benoît" que reunía a amigos e intelectuales y ejerció una gran influencia sobre la vida intelectual parisina entre 1940 y 1960. Resistente bajo la Ocupación nazi, comunista heterodoxo, participa en el combate anticolonialista durante la Guerra de Argelia. Paralelamente a su actividad política e intelectual, fue un actor discreto pero decisivo del mundo editorial francés. En 1942 entra como lector en Gallimard donde seguirá su carrera profesional.

12 "Réunir quelques-uns des meilleurs romans étrangers présentés par des écrivains français connus et dont l'autorité garantisse au lecteur, parmi le nombre considérable des traductions de toutes langues, une qualité littéraire certaine. C'est par cette collection qu'ont été révélés Lawrence, Faulkner et Kafka. Tirage restreint numéroté, sur alfa, sous une couverture spéciale, et constituant authentiquement l'édition originale de chaque ouvrage ci-dessous" (Catalogue des Éditions de la NRF, 1936), <http://www.gallimard.fr/Catalogue/GALLIMARD/Du-mondeentier> (última visita : 25/05/2020).

13 Los informes no se conservan en los archivos de la editorial parisina, pero Goytisolo informa regularmente a Puig de los avances de las lecturas y le transcribe las cartas de otros lectores, en especial la de Maurice Coindreau, "el capo": "J’ai lu le manuscrit argentin et trouve le livre excellent, surtout la première partie. Il y a là un mélage de fantaisie et de réalité, de drôlerie et de crudité très savoureux. De plus la facture en est originale. J'enverrai certainement un avis favorable" (Puig 2006: 252). 
pales críticos y traductores de literatura hispanohablante en Francia ${ }^{14}$. Si bien no critica la novela, Claude Couffon no muestra el mismo entusiasmo que los otros lectores consultados por el editor de la colección.

Por otra parte, desde octubre de 1966, en la correspondencia interna se evoca, aunque con cierta duda y reticencia, la posibilidad de consultar a Roger Caillois. De hecho, se contacta tarde al director de la Croix du Sud, solamente en enero de 1967, y para anunciarle que la novela ha sido comprada ya. Pocos días después, en una escueta nota, Caillois, que entiende perfectamente que fue informado por simple cortesía, confirma que la novela es "demasiado porteña” (escribe la palabra en castellano y la subraya) "para la Croix”. Lo más notable en esta primera fase del proceso editorial, es la decisión de dejar fuera a las figuras hasta entonces centrales de legitimación de la literatura latinoamericana en Gallimard, Claude Couffon y Roger Caillois. Desde el principio de los años sesenta, la pionera colección francesa de literatura latinoamericana sufría los ataques de los escritores latinoamericanos a quienes empezaba a "aparecer como un ghetto, un espacio que marginaliza las obras al negar su valor universal mientras que los escritores latinoamericanos aspiran a recibir un reconocimiento estético y no solo suscitar un interés como productores de documentos culturales” (Louis 2013: 81). La crítica venía también del propio campo editorial francés, que proponía otras lecturas, como el dossier "Nouveaux écrivains d'Amérique latine” preparado por Octavio Paz para la revista Lettres nouvelles en 1961. Desde la introducción del número, el editor de la revista y crítico respetado, Maurice Nadeau, pretendía ofrecer a los lectores franceses un "aggiornamento [. . . ] no ya una literatura de contenido social, inspiración folclórica o compromiso político, sino otra que ha sido ignorada y que permite descubrir el verdadero nivel de desarrollo actual de las técnicas poéticas y novelescas en el continente latinoamericano" (Guerrero 2018: 206). La clara decisión de apartar a Caillois de la publicación de la novela de Puig, aunque llevada a cabo con la elegante diplomacia que caracteriza la editorial, muestra que el rumor del cambio había llegado hasta la propia casa de la Croix.

No cabe duda de que La traición de Rita Hayworth no respondia a los criterios de representatividad cultural que definía la literatura latinoamericana presentada por Caillois al lector francés. Es de suponer que la decisión de publicarla en la otra colección de literatura extranjera "Du monde entier", la hermana menor de "La Blanche”, es una señal de que se va gestando en Gallimard otra concepción de la literatura latinoamericana, ni etnográfica ni rural, menos sesgada por las

14 Si bien el papel de Claude Couffon (1926-2013) en la difusión de la literatura hispanoamericana es decisivo, son todavía escasos los trabajos que le están dedicados. Véase BreysseChanet/Salazar (2014). 
ciencias sociales, este filtro de lectura y selección de la literatura latinoamericana que se había impuesto con la Croix (Guerrero 2018: 208) y que la novela de Puig goza de una lectura literaria que toma en cuenta su valor estético intrínseco.

Sin embargo, el peritexto editorial invita a matizar tanto optimismo. Se compone de dos documentos, el "prière d'insérer"15 conservado en los archivos de Gallimard y el texto de la contraportada de la edición de 1969 que retoma de manera casi idéntica la misma presentación. El primero, el texto de presentación redactado por la editorial y que acompañaba los ejemplares enviados a la crítica, propone un retrato de Puig que desconoce por completo su modernidad estética. En efecto, compara a Puig con el "Douanier Rousseau", el pintor que con sus retratos de familias burguesas que parecen ignorar las leyes de la perspectiva y sus selvas pobladas de indígenas soñadoras y animales salvajes era el blanco de mofas favorito de los salones de pintura del París de fin-desiglo antes de ser rescatado por Picasso y reconocido como un predecesor por los surrealistas. El símil da lugar a una caracterización de Puig que, como era de esperar, rezuma paternalismo y condescendencia. Como el pintor de estilo infantil, Puig, con su “absoluta sencillez inocente y perversa a la vez", desenmascara las mentiras de la sociedad, la "alienación que ejerce la "cultura" cinematográfica”. La interpretación que proponen el "prière d'insérer” a los críticos y luego la contraportada a cada lector de la novela niega, o simplemente ignora, la contemporaneidad estética de Puig, valga decir la de un escritor latinoamericano, con el pop art, movimiento que era en ese entonces la expresión cultural más moderna. No debe extrañar tanto que en el "Meridiano de Greenwich” del mundo literario, no sea posible reconocerlo. ¿Cómo un escritor argentino podría infringir la ley temporal del universo literario según la cual "hace falta ser antiguo para pretender ser moderno o decretar la modernidad" (Casanova 2008: 137)? Aunque, probablemente, lo que el autor de este texto no puede reconocer, es la emergencia del pop-art, y su manera de borrar la jerarquía entre cultura alta y de masas. Admitirlo obliga a reconocer, en este caso, que existe una cultura cinematográfica, sin ponerla entre comillas.

A modo de conclusión, se pueden destacar dos puntos. Primero, los archivos de Seuil y Gallimard confirman el papel decisivo que desempeñó el medio editorial francés en la difusión internacional de la obra de Puig, ya que el interés precoz de los editores propició su participación en la génesis de la novela.

15 El término "Prière d'insérer" que designa una "hoja impresa que contiene indicaciones sobre una obra y que es adjuntada a los ejemplares que se envían a la crítica” se conserva en su lengua original en la traducción al español de Seuils (1987), libro en el cual Gérard Genette analiza la evolución histórica de este elemento del peritexto editorial que es "al menos en Francia, uno de los elementos más característicos del paratexto moderno”. Ver Genette (2001: 91). 
Desde un punto de vista metodológico, un caso como este nos invita a incluir los archivos editoriales en el análisis genético de las obras.

Segundo y finalmente, la presencia editorial francesa se debe a la intervención de una figura híbrida como la de Sarduy, que como crítico latinoamericano y editor francés hace de puente permanente entre los medios y sus diferentes códigos y discursos. El hecho de que su lectura de la novela, la más afín a la crítica latinoamericana y al proyecto del propio escritor, no haya triunfado, muestra a la vez los límites de la intervención individual de los solitarios "passeurs" y recíprocamente el peso de las costumbres colectivas de lectura que finalmente triunfaron en la presentación editorial de La trahison de Rita Hayworth.

\section{Bibliografía}

Almada Roche, Armando (1992): Buenos Aires, cuándo será el día que me quieras.

Conversaciones con Manuel Puig. Buenos Aires: Editorial Vinciguerra.

Amar Sánchez, Ana María (1998): “Política y placer: las relaciones del mal gusto”. En:

Amícola, José/Speranza, Graciela (eds.): Encuentro Internacional Manuel Puig. Buenos

Aires: Beatriz Viterbo Editora, pp. 137-143.

Breysse-Chanet, Laurence/Salazar, Ina (eds.) (2014): “Dossier 'En hommage à Claude

Couffon””. En: Iberic@l 6, pp.151-190.

Casanova, Pascale (2008): La république mondiale des lettres. París: Seuil.

Catelli, Nora (1982): “Una narrativa de lo melifuo. Entrevista con Manuel Puig”. En: Quimera:

Revista de Literatura 18, pp. 22-25;

Corbatta, Jorgelina (2009): Manuel Puig, Mito personal, historia y ficción. Buenos Aires:

Corregidor.

de Diego, José Luis (1998): “Notas sobre exilio y literatura”. En: Amícola, José/Speranza,

Graciela (eds.): Encuentro Internacional Manuel Puig. Buenos Aires: Beatriz Viterbo

Editor, pp. 227-236.

Dosse, François (2014): Les hommes de l'ombre. Portraits d'éditeurs. París: Perrin.

Genette, Gérard (2001): Umbrales. Trad. Susana Lage. Buenos Aires: Siglo veintiuno editores.

Genette, Gérard (1987): Seuils. París: Seuil.

Giordano, Alberto (1998): “La serie Arlt-Cortázar-Puig”. En: Amícola, José/Speranza, Graciela

(eds.): Encuentro Internacional Manuel Puig. Buenos Aires: Beatriz Viterbo Editora, pp. 61-69.

Giordano, Alberto (1996): “Manuel Puig: los comienzos de una literatura menor”. En: Orbis Tertius $1 / 2-3$, pp. 255-274.

Goldchluk, Graciela/Romero, Julia (1996) “Manuel Puig: los comienzos de un escritor”. En: CELEHIS 3, pp. 385-395.

Guedán, Manuel (2018): Literatura Max Factor. Manuel Puig y los escritores corruptos latinoamericanos. Madrid: Punto de vista editores.

Guerrero, Gustavo (2018): “La Croix du Sud (1945-1970): génesis y contextos de la primera colección francesa de literatura latinoamericana”. En: Müller, Gesine/Locane, Jorge J./ 
Loy, Benjamin (eds.): Re-mapping World Literature: Writing, Book Markets and Epistemologies. Berlín/Boston: De Gruyter, pp. 199-208.

Levine, Suzanne Jill (2002): Manuel Puig y la mujer araña. Su vida y ficciones. Barcelona: Editorial Seix Barral.

Louis, Annick (2013): “Etoiles d’un ciel étranger. Roger Caillois et l’Amérique latine”. En: Littérature 170, pp. 71-81.

Ouvry-Vial, Brigitte (2007): “L’acte éditorial: vers une théorie du geste”. En: Communication et Langages 154, pp.67-82.

Páez, Roxana (1995): Manuel Puig. Del pop a la extrañeza. Buenos Aires: Almagesto.

Pauls, Alan (1986): Manuel Puig. La traición de Rita Hayworth. Buenos Aires: Hachette.

Puig, Manuel (2006): Querida familia. Tomo 2. Cartas americanas. Nueva York-Río (1963-1983). Compliación y notas de Graciela Goldchluk. Buenos Aires: Entropía.

Puig, Manuel (1969a): Boquitas Pintadas. Buenos Aires: Editorial Sudamericana.

Puig, Manuel (1969b): La trahison de Rita Hayworth, traducción de Laure Guille-Bataillon. París: Gallimard.

Rodríguez Monegal, Emir (1972): “El folletín rescatado”. En: Revista de la UNAM 27, pp. 25-35. Rodríguez Monegal, Emir (1967): “Nueva narrativa argentina”. En: Mundo Nuevo 18, pp. 21-31. Romero, Julia (2007): Puig por Puig. Imágenes de un escritor. Madrid/Fráncfort del Meno: Iberoamericana/Vervuert.

Speranza, Gabriela (2003). Manuel Puig. Después del fin de la literatura. Barcelona: Norma Editorial. 
